\title{
Mental Health and the Global Agenda
}

\section{Citation}

Becker, Anne E., and Arthur Kleinman. 2013. "Mental Health and the Global Agenda." New England Journal of Medicine 369 (1) (July 4): 66-73. doi:10.1056/nejmra1110827.

\section{Published Version}

10.1056/nejmra1110827

\section{Permanent link}

http://nrs.harvard.edu/urn-3:HUL.InstRepos:34360745

\section{Terms of Use}

This article was downloaded from Harvard University's DASH repository, and is made available under the terms and conditions applicable to Other Posted Material, as set forth at http:// nrs.harvard.edu/urn-3:HUL.InstRepos:dash.current.terms-of-use\#LAA

\section{Share Your Story}

The Harvard community has made this article openly available.

Please share how this access benefits you. Submit a story.

Accessibility 
3. Châtelet V, Lobbedez $T$, Frémeaux-Bacchi V, Ficheux $M$, Ryckelynck JP, Hurault de Ligny B. Eculizumab: safety and efficacy after 17 months of treatment in a renal transplant patient with recurrent atypical hemolytic-uremic syndrome: case report. Transplant Proc 2010;42:4353-5.
4. Pickard AS, Neary NP, Cella D. Estimation of minimally important differences in EQ-5D and VAS scores in cancer. Health Qual Life Outcomes 2007;5:70. [Erratum, Health Qual Life Outcomes 2010;8:4.]

DOI: 10.1056/NEJMc1308826

\section{Mental Health and the Global Agenda}

TO THE EDITOR: Becker and Kleinman (July 4 issue $)^{1}$ highlight the burden of mental diseases worldwide. Major concerns are for people living in less-developed countries (because of the low level of resources devoted to neuropsychiatric illnesses) and for young people (because of the difficulty accessing mental care).

We would like to emphasize the enormous suffering associated with mental disorders in older people. The prevalence of mental diseases in older people has increased dramatically in the past decades, not only because of aging itself (e.g., Alzheimer's disease), but also because of new emotional and sociodemographic situations to which the elderly are exposed. ${ }^{2}$ Moreover, disorders such as depression and dysthymia often become chronic, and the link between mental and physical health (ultimately leading to disability) is extremely strong. ${ }^{3}$ Finally, the use of psychotropic medications without fair evidence of safety, efficacy, and effectiveness in persons who are already receiving many other medications is fraught with danger. Training primary care clinicians in the care of elderly patients with mental illness should be a priority.

Alessandra Marengoni, M.D., Ph.D.

Sergio Pecorelli, M.D., Ph.D.

University of Brescia

Brescia, Italy

marengon@med.unibs.it

No potential conflict of interest relevant to this letter was reported.

1. Becker AE, Kleinman A. Mental health and the global agenda. N Engl J Med 2013;369:66-73.

2. Marengoni A. The era of aging children and elderly parents: something new in emotional epidemiology. J Am Geriatr Soc 2010;58:1622.

3. Skoog I. Psychiatric disorders in the elderly. Can J Psychiatry 2011;56:387-97.

DOI: 10.1056/NEJMc1309899

TO THE EDITOR: In their article, Becker and Kleinman articulate the critical steps needed to improve global mental health care. One of us is a Ghanaian medical student, and we would respectfully add that persons involved in the discourse on global mental health also need to en- gage indigenous mental health care systems. These systems, which fall outside the hegemonic discourse of Western psychiatry, include traditional healers and faith-based practitioners. In Ghana, it is estimated that there are 45,000 traditional "healers" - far more than there are psychiatrists, psychologists, social workers, and mental health nurses. ${ }^{1}$ These indigenous forms of healing are widely used, in part, because they operate within ingrained cultural beliefs about mental illnesses, ${ }^{2}$ and although there is limited research, there is some evidence that traditional healers are effective in offering certain mental health services. ${ }^{3}$ Although legitimate concerns have been raised about human rights abuses and the scientific validity of forms of treatment in traditional medicine, these caregivers shoulder a considerable burden of care delivery and offer an important avenue through which capacity can be developed, stigma can be reduced, and quality can be improved.

Akosua A. Korboe, B.A.

University of Rochester School of Medicine and Dentistry Rochester, NY

Julia Carney, B.A.

Massachusetts General Hospital

Boston, MA

No potential conflict of interest relevant to this letter was reported.

1. Roberts H. Accra: a way forward for mental health care in Ghana? Lancet 2001;357:1859.

2. Ae-Ngibise K, Cooper S, Adiibokah E, Akpalu B, Lund C, Doku V. 'Whether you like it or not people with mental problems are going to go to them': a qualitative exploration into the widespread use of traditional and faith healers in the provision of mental health care in Ghana. Int Rev Psychiatry 2010;22:558-67. 3. Abbo C, Okello ES, Musisi S, Waako P, Ekblad S. Naturalistic outcome of treatment of psychosis by traditional healers in Jinja and Iganga districts, Eastern Uganda - a 3- and 6 months follow up. Int J Ment Health Syst 2012;6:13.

DOI: 10.1056/NEJMc1309899

the aUthors Reply: Marengoni and Pecorelli raise an important point about the large and growing mental health burden in older persons. Indeed, the formidable burden imposed by Alz- 
heimer's disease and other dementias (assessed according to disability-adjusted life years measured for all ages) increased by an estimated $99.3 \%$ between 1990 and 2010, ${ }^{1}$ and associated years lived with disability (YLDs) are on par with or exceed YLDs associated with diseases such as tuberculosis, the human immunodeficiency virus and the acquired immune deficiency syndrome, and malaria. ${ }^{2}$ Key strategies for leveraging scarce resources to provide accessible and high-quality mental health services - including integration across care delivery platforms, collaborative care, and task sharing - hold equal promise for disorders that disproportionately affect the elderly. The problem is that few services for dementia care have been implemented in poor countries, and elder care in richer countries is still inadequate.

We endorse the argument made by Korboe and Carney that indigenous mental health care systems, which are currently marginalized and underused in mainstream practice, can be mobilized to benefit their communities. Over the past five decades, it has repeatedly been shown that tapping assets in the folk and popular sectors of care can expand the repertoire of therapeutics and hone the cultural fit of interventions. The limits and misuses of indigenous care also have been shown. Regrettably, advances in the implementation of traditional interventions have still been inadequate, but rigorous evaluation of the effectiveness of interventions aligns with priorities set out in the ambitious global research agenda for mental disorders. ${ }^{3}$

Anne E. Becker, M.D., Ph.D.

Harvard Medical School

Boston, MA

Arthur Kleinman, M.D.

Harvard University

Cambridge, MA

kleinman@wjh.harvard.edu

Since publication of their article, the authors report no further potential conflict of interest.

1. Murray CJL, Vos T, Lozano R, et al. Disability-adjusted life years (DALYs) for 291 diseases and injuries in 21 regions, 19902010: a systematic analysis for the Global Burden of Disease Study 2010. Lancet 2012;380:2197-223.

2. Vos T, Flaxman AD, Naghavi M, et al. Years lived with disability (YLDs) for 1160 sequelae of 289 diseases and injuries 1990-2010: a systematic analysis for the Global Burden of Disease Study 2010. Lancet 2012;380:2163-96.

3. Collins PY, Patel V, Joestl SS, et al. Grand challenges in global mental health. Nature 2011;475:27-30.

DOI: 10.1056/NEJMc1309899

\section{Primaquine Failure and Cytochrome P-450 2D6 in Plasmodium vivax Malaria}

TO THE EDITOR: Primaquine is the only medication approved by the Food and Drug Administration to eradicate the hypnozoites of Plasmodium vivax, but relapses of $P$. vivax malaria due to drug failure occur. ${ }^{1}$ Human cytochrome P-450 isoenzyme 2D6 (CYP2D6) may be a key enzyme involved in metabolizing primaquine into redoxactive metabolites against hypnozoites in the liver. ${ }^{2,3}$

As part of a phase 1 clinical trial of a vaccine against P. vivax (Study of VMP001 and AS01B in Healthy Malaria-Naive Adults; ClinicalTrials.gov number, NCT01157897), 33 participants were exposed to P. vivax sporozoites from the bites of infected mosquitoes. Parasitemia developed in all participants by day 13 after the challenge, and parasitemia rapidly cleared on initiation of the directly observed administration of a combination of chloroquine (at a dose of $1500 \mathrm{mg}$ base by mouth over a period of 48 hours) and primaquine (at a dose of $30 \mathrm{mg}$ by mouth daily for 14 days). Two participants (6\%) had multiple relapses of malaria (see Fig. 1 in the Supplementary Appendix, available with the full text of this letter at NEJM.org). After each relapse, parasitemia was rapidly cleared in these participants with chloroquine (at a standard dose of $1500 \mathrm{mg}$ base by mouth over a period of 48 hours) and a weight-based dose of primaquine (at a total dose of $6 \mathrm{mg}$ per kilogram of body weight). To our knowledge, true resistance to primaquine in $P$. vivax hypnozoites has not been described; this suggests a role for host factors in drug failure. ${ }^{1}$ We sought to identify an association between CYP2D6 activity and primaquine drug failure.

CYP2D6 phenotypes were ascertained in 25 available participants. The institutional review boards of the Walter Reed Army Institute of Research, the Naval Medical Research Center, and the Walter Reed Army Medical Center, as well as the Western Institutional Review Board approved the study, and all participants provided written informed consent. CYP2D6 phenotyping was performed; 21 participants had an extensive- 